DOI: $10.35643 /$ Info.26.1.13

Artículo original

\title{
Desigualdad digital y usos de Internet en telecentros públicos: dilemas y desafíos de los Espacios de Inclusión Digital en Uruguay
}

Digital inequality and Internet uses in public telecentres: dilemmas and challenges of Digital Inclusion Spaces in Uruguay

Desigualdade digital e usos da Internet em telecentros públicos: dilemas e desafios dos espaços de inclusão digital no Uruguai

\author{
Ana Laura Rivoir ${ }^{\mathrm{a}}$ \\ Santiago Escuder ${ }^{b}$
}

\begin{abstract}
${ }^{a}$ Profesora agregada e investigadora del Departamento de Sociología - Facultad de Ciencias Sociales. Doctora por la Universidad Abierta de Catalunya. Coordinadora del grupo ObservaTIC. ORCID: 0000-0001-5677-2585. Correo electrónico: ana.rivoir@cienciassociales.edu.uy

${ }^{\mathrm{b}}$ Profesor e investigador asistente del Departamento de Sociología - Facultad de Ciencias Sociales y la Unidad Central de Educación Permanente. Magister en Sociología por la Universidad de la República. Integrante grupo ObservaTIC. ORCID: 0000-0003-0041-5831. Correo electrónico: santiago.escuder@,cienciassociales.edu.uy
\end{abstract}

\section{Resumen}

El siguiente trabajo explora las posibilidades de apropiación de los usuarios que acuden a Espacios de Inclusión Digital (EID), telecentros locales provistos por la empresa estatal telecomunicaciones de Uruguay (ANTEL) como parte de las políticas sociales TIC del país. A través de un censo a usuarios y técnicas de análisis multivariado, se analizan los usos que realizan los internautas de estos espacios y conocer si contribuye esta iniciativa a la reducción de la brecha digital en su acepción más compleja, es decir no sólo referida a la conectividad sino a los usos y su interacción con otras dimensiones. De acuerdo a los hallazgos, la apropiación digital ocurre de acuerdo a diferentes perfiles socio-demográficos de los usuarios de los EID, siendo las mujeres y los jóvenes más formados los que se benefician más del uso de Internet en estos espacios. Se concluye que la contribución a la reducción de la brecha se logra en relación a un grupo muy limitado de usuarios.

Palabras clave: DESIGUALDAD DIGITAL; TELECENTROS; POLÍTICAS; TIC. 


\begin{abstract}
The following work explores the possibilities of appropriation of the users who go to Digital Inclusion Spaces (EID), local telecentres provided by the state company ANTEL as part of the ICT social policies of Uruguay. Through a census of users and multivariate analysis techniques, we seek to know what uses Internet users make of these spaces, how much this initiative fulfills the tasks of reducing the digital divide, understood in its complex conception. According to the findings, digital appropriation occurs according to different socio-demographic profiles of the users of the EID, being women and the most educated young people who benefit the most from the use of the Internet in these spaces. We conclude that the contribution to the reduction of the digital divide is achieved in relation to a very limited group of users.
\end{abstract}

Keywords: DIGITAL INEQUALITY; TELECENTERS; POLICIES; TIC.

\title{
Resumo
}

O trabalho a seguir explora as possibilidades de apropriação pelos usuários que frequentam os Espaços de Inclusão Digital (EID), telecentros locais fornecidos pela empresa estatal de telecomunicações do Uruguai (ANTEL) como parte das políticas sociais de TIC do país. Através de um censo de usuários e de técnicas de análise multivariada, são analisados os usos que os internautas fazem desses espaços e para saber se esta iniciativa contribui para a redução da exclusão digital no seu sentido mais complexo, ou seja, não apenas no que se refere à conectividade, mas também à usos e sua interação com outras dimensões. De acordo com os achados, a apropriação digital ocorre de acordo com os diferentes perfis sociodemográficos dos usuários do EID, sendo as mulheres e os jovens mais escolarizados os que mais se beneficiam do uso da Internet nesses espaços. Conclui-se que a contribuição para a redução do gap é alcançada em relação a um grupo muito limitado de usuários.

Palavras-chave: DESIGUALDADE DIGITAL; TELECENTERS; POLÍTICAS; TIC.

Fecha de recibido: $08 / 10 / 2020$

Fecha de aceptado: 13/04/2021

\section{Introducción}

\subsection{La desigualdad digital}

En las sociedades contemporáneas, el uso de las Tecnologías de la Información y la Comunicación (TIC) ha provocado distintos procesos, muchos de los cuales son 
muy positivos y favorecen el desarrollo de las personas. Sin embargo, la distribución desigual de estos beneficios provoca también nuevas desigualdades.

Según Reygadas (2008), se retroalimentan las desigualdades a nivel individual las características y capacidades de las personas- y las externas - los recursos, políticas y contexto. Generan una nueva segmentación social. Se trata de “desigualdades por desconexión" pues se vinculan a desigualdades en el acceso al conocimiento científico y tecnológico y a su uso, a la participación de los ciudadanos en la economía del conocimiento y a las redes de educación, producción y empleo (Reygadas, 2008).

Es así que se conforma la brecha digital como la desigualdad característica del siglo XXI, expresada en las diferencias en el acceso y el uso del espacio virtual. Se basa en una ausencia de acceso a infraestructura de TIC y en el uso precario, conformando así una nueva desigualdad social (Norris, 2001; Lash, 2002; Kaztman, 2010; Rivoir, 2012; Jang, Hessel y Dworkin, 2017). Es un concepto complejo que no se reduce al mero acceso, sino que es multidimensional debido a su interacción con otras desigualdades y por tal motivo se asocia a variables como edad, género, etnia, tipo de ocupación y nivel educativo. (DiMaggio et al. 2004; Rivoir 2013; Selwyn 2004).

Se configura asimismo un segundo nivel de la brecha digital referido a los usos y la apropiación de las TIC y que también mostró estar vinculado a las características sociodemográficas de la población y las habilidades de las personas (DiMaggio et al., 2004; Selwyn, 2004; Van Dijk, 2005; Hargittai y Hinnant, 2008). Van Dijk (2012) y Selwyn (2004) reconocen factores individuales como las motivaciones personales o el capital social - como tener una red de contención, parientes, amigos, que ayude a utilizar la tecnología-, incluso la inversión de tiempo necesaria para utilizar los dispositivos de TIC.

Finalmente, puede referirse a un tercer nivel del análisis de las desigualdades digitales que remite a los resultados tangibles del uso sobre las condiciones de vida de las personas (Lamschtein y Rivoir, 2016) Refiere a los resultado que los usos efectivos tienen sobre la vida de las personas, su calidad de vida y desarrollo (Livingstone y Helsper, 2010; Van Deursen y Van Dijk, 2014a). 
Es así que la denominada brecha digital o desigualdad digital es un fenómeno complejo, ante el que es conveniente tomar en cuenta todas las dimensiones y analizar su interacción con otras desigualdades existentes. Comprenderla en contexto y trascender el análisis del mero acceso y uso, así como tomar en consideración las competencias y habilidades digitales de las personas para utilizar las TIC. Es un fenómeno que es influido también por las políticas públicas $\mathrm{y}$ acciones que se toman para su reducción y por tal motivo, los efectos de dichas intervenciones debe ser un factor a considerar. Esto permite a su vez sopesar y comprender cuánto logran estas políticas reducir la desigualdad digital $\mathrm{y}$, eventualmente, otras desigualdades.

Particularmente en Latinoamérica, existe una segregación profunda en las ciudades, la zonas metropolitanas y sus periferias en ella se requiere de niveles avanzados de información, gestión del conocimiento y procesos de innovación comunitarios en un contexto de desarrollo informacional acelerado (Finquelievich, 2004).

\subsection{Telecentros e inclusión digital}

La acumulación de conocimiento sobre las desigualdades digitales fue evidenciando que son necesarias políticas públicas para su reducción. Esto incluye las condiciones de la infraestructura digital hasta las iniciativas para la adquisición de competencias por parte de la población. Asimismo, si se espera que contribuyan al desarrollo humano también debe estar previsto esto en la concepción de los actores políticos y la política pública. (Peña - López, 2009; Guerra y Jordán, 2010; Gascó, Equiza y Acevedo, 2007; Rivoir, 2012)

Por otra parte, un factor es la importancia de los actores involucrados, el arraigo cultural y la consideración del contexto son elementos fundamentales que han sido señalados en distintos estudios precursores del estudio de iniciativas para el uso comunitario en América Latina y en Uruguay en particular (Camacho, 2001; Bonilla y Cliche, 2001, Martinez, 2001; Finquelievich, 2000; Sabelli, 2008).

La creación de telecentros o centros de acceso público, forman parte de las iniciativas de política pública o comunitaria, orientadas a reducir la desigualdad o brecha digital con distintos enfoque y metodologías. Celedón y Razzeto (2009) los 
definen como centros orientados a personas y grupos con algún grado de dificultad o barrera para el acceso, producto de su situación de vulnerabilidad social o alejamiento geográfico. Según de la Maza, Maeso, Gutiérrez y Wohlers (2007) se encuentran por un lado los que tienen un enfoque comercial y se orientan por la lógica del mercado. Acceden a ellos quienes pueden pagar sus servicios y son, por lo general, pequeños negocios en las ciudades, denominados cibercafés. Por otro, los de enfoque social que incluye los telecentros y otros centros de acceso público a las TIC impulsados por gobiernos, Organizaciones No Gubernamentales (ONG) $\mathrm{u}$ otros actores de desarrollo que promueven e implementan programas y proyectos para facilitar el acceso a las TIC para distintos sectores de la población.

En América Latina se inició la década de los noventa, con un sinfín de propuestas para introducir el acceso colectivo (Robinson, 2001).

Se plantea así la imposibilidad de modelos universales y la importancia de considerar la especificidad del contexto cultural donde se instalan y que contemplen las necesidades de los usuarios y constituyan espacios de promoción comunitarios. (Gómez et alt, 1999; Delgadillo, Gómez y Stoll, 2002)

En una fase muy inicial y experimental, los telecentros se orientaron a ser formas de solución de los problemas del desarrollo a través del acceso a las TIC. Sin embargo, esto derivó en una diversidad de experiencias dentro de las cuales muy pocos tuvieron vinculación con ese objetivo inicial. (Gómez et alt, 1999). En una segunda fase, estos espacios de acceso comunitario pasan a cumplir un rol de desarrollo social, mostrando cierta practicidad y/o utilidad para contribuir al desarrollo local de una región o municipio (Martínez, 2001).

Los resultados sobre estas experiencias son diversos. Credé y Mansell (1998), destacan experiencias de telecentros comunitarios que habían logrado cumplir con objetivos de mejorar las condiciones de vida de personas y comunidades excluidas. A partir de iniciativas para la salud, las gestiones de gobierno, educación acceso a información, protección de recursos naturales locales y así el desarrollo social y comunitario contribuyen en ese sentido. Aunque Delgadillo, Gómez y Stoll (2002) también alertan sobre el riesgo de que los telecentros sean 
meros centros para entretenimiento y consumo, sin contribución a la mejora de las condiciones de vida de la gente ni con el desarrollo humano.

Otros autores (Barón y Gómez, 2012) encuentran que si bien el uso de computadores de acceso público puede lograr experiencias de empoderamiento y de desarrollo de capital social, no encuentran vínculos entre las capacidades de información y comunicación y las oportunidades de las personas. Más bien contribuye a su autoestima, la sensación de pertenencia a un mundo mayor con otras personas y culturas, la satisfacción de necesidades individuales de comunicarse con amigos y familiares o mantenerse en contacto con personas, incluso nuevos entretenimientos.

A partir de un extenso estudio, Proenza (2015) encuentra diferente tipo de resultados según el contexto socio-cultural. Encuentra que el acceso público permite a la mayoría de los usuarios alcanzar objetivos personales como aprender, comunicarse con familiares y amigos, mejorar las habilidades laborales y las perspectivas laborales (Ruanda) y entretenerse (China). Contribuye a expandir sus redes sociales y construir capital social (Malasia y Jordania), facilita la inclusión social (Argentina) y habilita a que las organizaciones rurales de base desarrollen capacidades como la interacción con agentes externos (Perú). Asimismo, encuentra que el uso excesivo que afecta negativamente el rendimiento escolar (Camerún) y distintas esferas de la vida personal (China). Los distintos casos dan cuenta de que la inmensa mayoría de los usuarios consideran que las TIC de acceso público han impactado positivamente en sus vidas, en el logro y bienestar personal, y en la expansión de redes y oportunidades para comunicarse, intercambiar ideas y colaborar. Los hallazgos de impacto positivo en Chile, Argentina y Tailandia dan cuenta de la posibilidad de diseñar e implementar iniciativas de telecentros con alto impacto y bien orientadas. (Proenza, 2015)

Celedón y Razzeto (2009) resaltan que estas iniciativas facilitan el desarrollo comunitario a partir del acceso a las TIC, si responden a las necesidades de las comunidades locales. Inicialmente, los centros tenían en común la participación de estudiantes como usuarios principales y posteriormente las iniciativas se orientaron a poblaciones más excluidas de la ciudad o de zonas más aisladas. Sostienen que los aspectos socioeconómicos no sólo restringen el acceso sino 
también se relacionan a la capacidad de uso efectivo de estas tecnologías. El desarrollo de conocimientos y habilidades se encuentra sesgado por el nivel educativo que a su vez se relaciona con el nivel de ingresos de las personas y por lo tanto debe ser considerado por la política. Concluyen que la actitud hacia la tecnología, el idioma y distintos aspectos culturales frenan su incorporación cotidiana y para darle sentido y significado al uso. Por último, refiere al condicionamiento del uso efectivo por la carencia de contenidos y aplicaciones que sean útiles para la población, pues es lo que le da sentido al uso. Por tanto, el desarrollo y la promoción del uso deben ser orientados a las necesidades de la población como el gobierno-e, comercio-e, educación-e, salud-e, entre otros.

Algo similar plantea Hallberg (2016) respecto a la planificación que se requiere tener en cuenta a la hora de desarrollar un programa de telecentros. Por un lado los aspectos socio-demográficos (el sexo, la edad, situación socio-económica), junto con aspectos específicos, como idioma, etnia, además de las expectativas de la comunidad.

Los operadores y operadoras constituyen un elemento estratégico. Más que técnicos en computación, son facilitadores de grupos de tareas de promoción comunitarias entre otros trabajos y actividades y por lo tanto, la formación que posean es clave. Incluso para la gestión del telecentro y la viabilidad del mismo. (Delgadillo, Gómez y Stoll, 2002; Celedón y Razzeto, 2009)

Según Delgadillo, Gómez y Stoll (2002) debido a políticas gubernamentales de conectividad, se pasó de 50 telecentros en la región en 1998 a 6500 estimados para 2002, sin incluir los cibercafés. Más recientemente Baca y otros (2018) encontraron que si bien, en primera instancia, algunos telecentros instalados en bibliotecas, escuelas, edificios gubernamentales, etc. parecieron ser efectivos, hacia 2012 muchos de ellos ya estaban abandonados y con muy baja asistencia debido a la falta de mantenimiento, baja calidad en los servicios, nulo vínculo con la comunidad en la que están y poco trabajo en la producción y acceso a contenidos pertinentes para los usuarios.

El contexto ha cambiado en términos de la expansión del acceso y la aparición de la telefonía móvil con acceso a Internet. Según datos de la Unión Internacional de Telecomunicaciones (UIT[1]), el acceso a algún tipo de computador (laptop y/o 
escritorio) para el 2018 alcanzaba en el mundo prácticamente al 47\% de los hogares, siendo en las Américas al 65\%. En el caso de acceso a Internet 55\% en el mundo, y un 67\% en las Américas. En Uruguay, según la Encuesta de Usos de Tecnologías de la Información y la Comunicación (EUTIC[2]), un 68\% de los hogares accede algún tipo de dispositivo en el hogar (no celular), y un $71 \%$ a banda ancha fija de Internet. No obstante, existen diferencias en el acceso considerables según quintiles de ingresos, siendo el quintil número uno el que menos accede a un computador en el hogar (47\%) y conexión por banda ancha fija a Internet (51\%).

Proenza (2015) señala a los teléfonos móviles como elementos que están ayudando a mitigar los efectos de las distintas limitaciones de las personas para el acceso. Permiten que las redes de comunicaciones atiendan las necesidades de los usuarios de bajos ingresos y las comunidades rurales y mayormente, también están al alcance de las mujeres. Sin embargo, en la práctica, sólo los teléfonos de banda ancha costosos y más sofisticados son los que permiten el intercambio interactivo necesario para construir redes sociales. Es así que de todas formas, el acceso a computadoras e Internet, es más adecuado para ayudar a las personas a aprender y desarrollarse, es decir, a mejorar sus posibilidades para aprender, encontrar trabajo e innovar.

Por su parte, Benítez Larghi y otros (2012), reivindican ante el avance masivo de la conectividad hogareña y la telefonía móvil, la función social de lo que llaman los distintos espacios de apoyo al acceso público, sobre todo por el rol que cumplen en la vida de los sectores populares y de sus jóvenes en particular. Concluyen que los contextos, antecedentes y biografías distintas así como los perfiles socioculturales diversos y distribución desigual de capitales condicionan los procesos de apropiación de las TIC. Descartan que los jóvenes sean "nativos digitales" y reivindican el apoyo a los procesos de apropiación en estos espacios de acceso público.

Se ha constatado que aunque las mujeres y los grupos desfavorecidos pueden beneficiarse significativamente del acceso público, el acceso suele ser limitado y esto en algunos países les afecta de forma grave. (Proenza, 2015; Peña, 2015) Otro sector que se aprovecha de estos espacios son las personas mayores pues es 
parte de la población que aún está afectada por la desigualdad digital. Específicamente, asisten para recibir apoyo para el uso de las TIC, siendo el acompañamiento y la contención en un entorno de confianza y amigable entre pares factores importantes. Asimismo, se destacan los facilitadores que les animan al aprendizaje en los usos y el desarrollo de habilidades y competencias digitales. (Rivoir y Escuder, 2018)

Respecto a la apropiación tecnológica dentro de estos espacios, existen múltiples trabajos de investigación en Bolivia, Paraguay, México y Brasil. Estos sugieren que las TIC en los telecentros son utilizadas básicamente para tres propósitos: buscar material educativo en caso de niños y adolescentes, realizar cursos de alfabetización digital y comunicarse con familiares mediante chat y/o redes sociales electrónicas (Duran, 2009; Escuder, 2010; Chamorro, 2014; Hallberg, 2016; Velloso y Castanheira, 2019). No obstante, existen casos particulares de apropiación con información "práctica", que se vinculan al trabajo de los usuarios, principalmente comerciantes y productores rurales que utilizan Internet para indagar acerca de los precios de los productos que comercian a través del mercado, consiguiendo nuevas oportunidades de colocación y desestimando intermediarios (Ramírez Plascencia, 2014). La mayoría de los estudios dan cuenta de problemas de infraestructura y sobre todo de velocidad de Internet en estos centros.

En suma, el surgimiento de telecentros como iniciativas de políticas públicas o de organizaciones sociales, formó parte de una serie de acciones que buscaron brindar acceso a TIC para reducir la desigualdad digital, sobre todo en los países más rezagados. Esta forma colectiva o comunitaria no comercial tuvo un auge a principio de siglo con la proliferación de políticas públicas e iniciativas comunitarias. Posteriormente, con la expansión de la telefonía móvil y el aumento de la conectividad en los hogares, comenzaron a desaparecer. Su función de brindar acceso fue mutando hacia un rol en la promoción del desarrollo de competencias digitales y la apropiación de estas tecnologías, sin desmedro del acceso que dista mucho de ser universal.

La necesidad de reducir la desigualdad digital en sus distintos niveles marca la vigencia de estos espacios colectivos públicos aunque con un rol diferente. Sin 
embargo, junto con el declive de los telecentros mermaron los estudios y análisis de distintos modelos, de sus metodologías para la apropiación y de sus logros en relación a la reducción de la desigualdad digital. Esto hace necesario retomar el análisis y su estudio en un contexto de uso creciente de tecnologías y de persistentes grupos excluidos digitalmente.

\section{Objetivos y metodología}

El objetivo principal de este artículo es presentar los resultados de una investigación que buscó conocer cuánto inciden los Espacios de Inclusión digital de la empresa estatal de telecomunicaciones de Uruguay ANTEL, en la disminución de las desigualdades digitales. A partir del estudio del público asistente, se propuso conocer en qué medida se producen procesos de reducción o reproducción de las desigualdades digitales analizando los usos por parte de usuarios con distintos perfiles.

Se aplicó un diseño metodológico cuantitativo (no experimental) para caracterizar a los usuarios de los telecentros a partir de: el perfil-socio-demográfico, el acceso y capacitación TIC, y el uso de Internet en el horario libre.

La técnica utilizada fue la realización de un censo telefónico a todos los usuarios, en el cual se aplicó una encuesta telefónica entre marzo y mayo del 2017. La muestra de casos no es representativa del total de la población objetivo pero permite una caracterización de los usuarios que acuden a los espacios, fundamentalmente aquellos que realizaron alguna instancia de formación o capacitación digital.

Se encuestaron un total de 206 usuarios de los 447 registrados en el censo, 73 de los no encuestados no contaban con un teléfono de contacto y 14 eran números equivocados. 80 de los contactados, luego de cinco llamados no se los re-contacto pese a ser casos potencialmente efectivos (rechazo encubierto). 33 usuarios rechazaron realizar la encuesta y 22 usuarios no recordaban haber utilizado el EID. Cuatro usuarios eran operadores y un usuario pertenecía al Instituto Nacional de Rehabilitación (INR) por lo que se consideró no oportuno contactarlo.

Dos hipótesis rivales junto con una hipótesis intermedia guiaron el trabajo. 
La primera hipótesis sostiene que los usuarios de los EID realizan un uso significativo de Internet más allá de las desigualdades sociodemográficas preexistentes que portan los usuarios. Es decir, una apropiación de Internet significativamente superior al promedio de uso a nivel nacional, donde predomina el uso predominantemente para comunicación y entretenimiento. Proceso que se consolida debido al acompañamiento y formación que brindan los profesores de alfabetización digital abriendo posibilidades de aprendizaje.

La segunda hipótesis sostiene lo contrario. Los usos dentro del EID no son diferentes al del resto de usos por parte de los uruguayos, sino que reproducen los tipos de uso promedio, por lo que no contribuyen a la reducción de las desigualdades en el uso según edad, el nivel educativo y demás variables sociodemográficas determinantes de la diferenciación en el uso.

La tercera hipótesis estaría conformada por una situación intermedia. Los EID logran mitigar algunas desigualdades digitales, pero no en todos los usuarios por igual. Dependerá de factores propios de la política TIC como el tiempo que los usuarios usan las instalaciones, si realizó algún curso de capacitación, entre otros factores.

\subsection{Técnicas y fuentes}

Se utilizó la técnica de Análisis de Correspondencia Múltiple (ACM) con el fin de explorar el fenómeno de la desigualdad digital entre los usuarios de los espacios EID. El ACM tiene la virtud de representar los datos en un plano cartesiano de dos dimensiones a partir de un análisis factorial lo que facilita la lectura y comprensión. Esta técnica permitió la construcción de posibles "mapas" de la brecha digital de acuerdo al perfil demográfico de los usuarios y uso de las instalaciones de los EID. Para agrupar los casos y construir "perfiles" de usuarios, se recurrió al "Agrupamiento jerárquico" utilizando el método de Ward para determinar los distintos "clusters". Estas técnicas permiten por un lado visualizar y agrupar aquellas unidades que guardan mayor similitud con mínima pérdida de información (Lopez Roldan y Fachelli, 2015). Por otro lado, la ACM es una técnica muy efectiva para segmentar a los usuarios y plasmar sus diferencias y las desigualdades sociales y digitales que portan los usuarios. Cuanto más cerca del 
punto de origen (coordenadas $\mathrm{x} 0$-y0), menor será la distancia entre los distintos usuarios, por ende tendrán mayor similitud en su apropiación. Cuanto más alejado, mayor será la heterogeneidad y niveles de apropiación de los EID.

Para procesar estos datos en el ACM se utilizó el programa informático Rstudio[3], el cual toma como base el motor estadístico "R", plataforma de software libre. Se utilizaron las librerías (extensiones) FactoMineR[4] para segmentar a los usuarios de los diferentes centros.

Los tipos de usos de Internet serán la variable suplementaria dentro del ACM, la cual actuará como variable dependiente para buscar diferencias de acuerdo a los diferentes perfiles ("clusters") de usuarios.

Las variables del Censo a usuarios de los EID utilizadas son las siguientes: el sexo del usuario (varón-mujer), la edad en tramos recodificados (10-17 años, 18-24 años, 25-40 años, 41-60 años, más de 60 años); el nivel educativo (primaria incompleta, primaria completa, secundaria incompleta, secundaria completa, terciario incompleto, terciario completo); posesión de PC en el hogar (computador de escritorio o laptop); acceso a la política TIC de Ceibal (XO), o Ibirapitá (Tableta); acceso a celular y; posesión de conexión a Internet en el hogar.

Por otro lado, se consultó si los usuarios llevaban al EID sus propios equipos y si habían hecho algún curso de capacitación. Por último, se consultó la antigüedad de concurrencia al EID (desde hace tres meses hasta más de tres años), la cantidad de días que acude (desde todos los días de la semana hasta menos de una vez por mes) y la cantidad de horas que acude en una visita común (desde menos de una hora hasta cinco horas).

\section{Resultados}

\subsection{Caracterización de los EID}

Los Espacios de Inclusión Digital, son telecentros a los que ANTEL aporta los equipos, programas y mobiliario, el servicio de acceso a Internet, la capacitación de los coordinadores y la instalación y el mantenimiento de los equipos informáticos. El programa fue creado en 2001 y ha beneficiado a distintas instituciones sin fines de lucro de todo el país. Se han consolidado mediante 
convenios con Intendencias, ONG's e instituciones privadas. Además de horario libre para el uso de las instalaciones, muchos de estos espacios cuentan con cursos de capacitación a los usuarios. Desde capacitaciones básicas de operador PC (Windows) a cursos de gestión de gobierno electrónico (trámites), así como más avanzados de diseño gráfico y otros determinados por los mismos referentes en coordinación con los usuarios. Contrario a otras iniciativas públicas los EID no tienen entre sus cometidos realizar actividades culturales. El programa cuenta actualmente con 78 centros abiertos, habiéndose relevado un número mayor en el año en que se desarrolló esta investigación[5].

En el marco de la investigación, se realizó un relevamiento de EID y se realizó una caracterización a los efectos de contextualizar el análisis de la encuesta de los usuarios. De los 98 EID relevados, 20 se sitúan en la capital Montevideo, 83 centros se encontraban en una institución pública (intendencia, ministerio, biblioteca, etc.), 6 de ellos formaban parte de una Organización Social Civil u Organización No Gubernamental. Finalmente, 5 estaban en otro tipo de institución y tan sólo dos centros eran gestionados por instituciones privadas. En cuanto a la antigüedad, el $7 \%$ se iniciaron entre 2001 y 2004; $48 \%$ entre 2005 - 2010 y $44 \%$ entre el 2011 y 2015. Sólo uno de los centros se había instalado en 2016.

En cuanto al nivel educativo de los encargados, un $46,9 \%$ de ellos contaba con estudios universitarios o superiores, 30,6\% habían finalizado secundaria, 17,3\% tenían hasta sexto de secundaria incompleto, 3\% hasta tercero de secundaria completo y tan solo dos encargados habían completado primaria. Consultados acerca de cómo consideran su conocimiento en informática, un $20,4 \%$ de los encargados consideró tener alto conocimiento de informática, 41,8\% medio alto, $36,7 \%$ medio, y tan sólo un encargado manifestó tener conocimiento bajo. Por otra parte, de los 98 encargados relevados, 93 conocían la plataforma Educa Antel (para capacitación) y 82 al menos tomaron algún tipo de curso en esta plataforma en el último año.

De acuerdo a lo informado al $21,3 \%$ de los centros acudían al menos diez usuarios por día, 35,1\% recibían de diez a veinte usuarios, 30,9\% entre 20 y 40 usuarios y 12,8 más de 40 usuarios. Tomando en cuenta el total de usuarios, en promedio acudirían diariamente más de 2300 usuarios a los EID. Según los encargados, un 
$8,6 \%$ de los usuarios utilizaban las instalaciones de los EID menos de 30 minutos por día, $52,7 \%$ entre 30 minutos y una hora, $29 \%$ de una a dos horas y $9,7 \%$ más de dos horas.

\subsection{Análisis descriptivo y principales características de los usuarios}

A los efectos de conocer la población de estudio, se presentan a continuación algunas características básicas de los usuarios de los EID. El 74\% de ellos eran mujeres y un 26\% varones. E1 30\% tiene entre 41 y 60 años de edad, $26 \%$ entre 25 y 40 años. Los usuarios de 61 y más sumaban 25\%, mientras que aquellos con más de 71 años no superan el 10\%. Los usuarios entre 18 y 24 años representaban el 10,8\% y entre los jóvenes de 14 y 17 años $6 \%$ al igual que los de entre 10 y 13 años.

En cuanto al nivel de instrucción, prácticamente la mitad de los usuarios $(47,3 \%)$ alcanzaban nivel secundario incompleto, 30\% nivel secundario completo o superior. Por debajo de este nivel, un $11,2 \%$ de los usuarios contaba con primaria completa y un $6,8 \%$ no habían logrado culminar este nivel.

Se relevó asimismo las condiciones de acceso e infraestructura de los hogares de los usuarios. En cuanto al equipamiento informático, el 48,3\% contaba con laptop, $30,7 \%$ con PC de escritorio (torre y monitor por separado) y $11,7 \%$ con tablet. La tenencia de dispositivos a través de la política social TIC, un $17,6 \%$ de los usuarios disponía en su hogar de una XO del Plan Ceibal y un 10,2\% tablet del Plan Ibirapitá. Finalmente, más de la mitad $(62,4 \%)$ tenían un celular inteligente y el 73,7\% accedían a algún tipo de conexión a Internet desde el hogar.

\subsubsection{Motivos, uso $y$ frecuencia de asistencia al EID}

Como se muestra en el gráfico $\mathrm{n}^{\circ} 1$, la gran mayoría de los usuarios encuestados (73,3\%) manifestó acudir al EID principalmente para realizar un curso de alfabetización digital. Por lo tanto, no es llamativo que la mayoría de usuarios registrados y posteriormente encuestados manifestaran haber realizado algún tipo de capacitación en los espacios.

Muy por debajo, un 10,7\% acudió por curiosidad, interés personal o para mantenerse actualizado. Como tercer motivo, un 9,2\% concurrió para realizar 
deberes y/o estudiar. Como cuarto motivo, un 2,9\% manifestó como principal motivación acudir para buscar información para trabajar $\mathrm{u}$ otro tema laboral. Menos del $1 \%$ de los usuarios manifestó utilizar el espacio para recrearse o mantenerse en contacto con amigos o familiares.

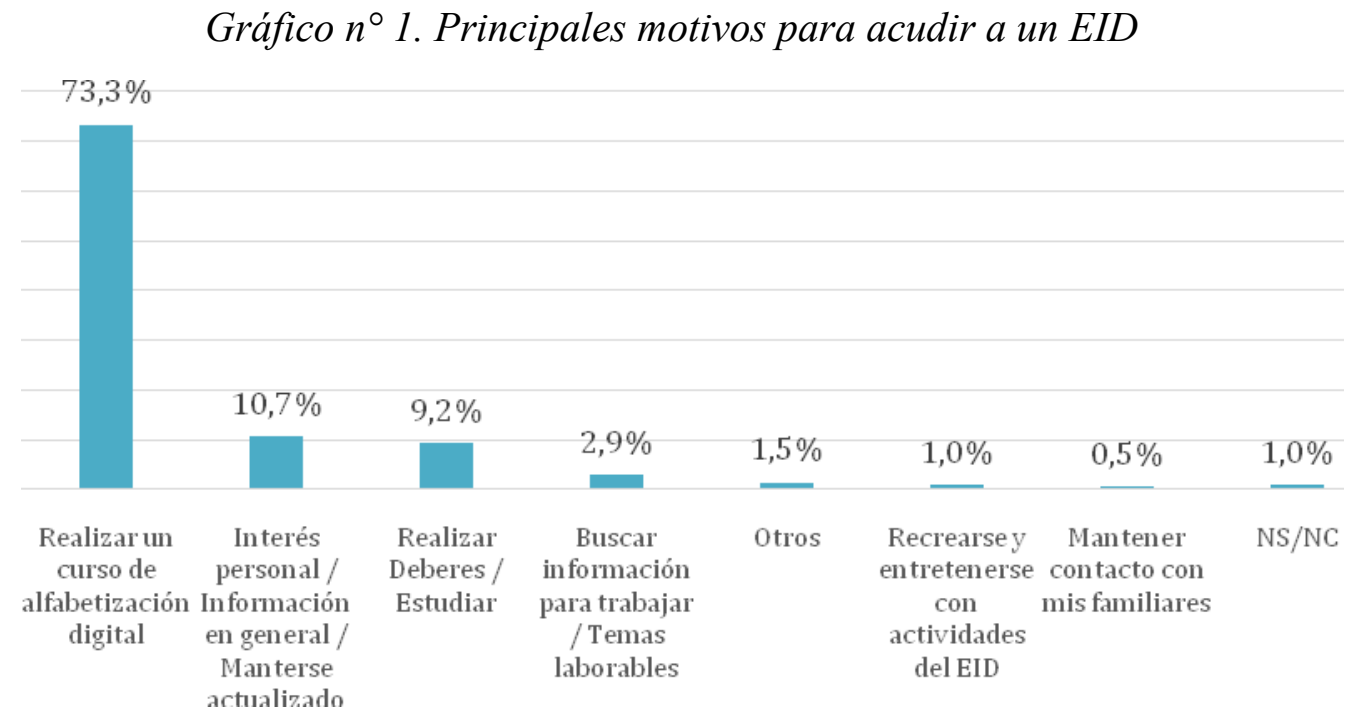

Fuente: procesamiento propio en base a relevamiento de usuarios - BASE: 206

El gráfico $n^{\circ} 2$ ilustra la antigüedad de los usuarios. Un $22,4 \%$ de los usuarios encuestados acudían al centro hacía menos de tres meses, 16,1\% hace menos de seis meses (pero más de tres meses) y un 14,1\% hace más de seis meses pero menos de un año. En el otro extremo 20,5\% de los usuarios acudían hace más de un año, 12,2\% hace más de dos años y un 14,6\% hace más de tres años. Es decir, prácticamente la mitad de los usuarios acudían hace menos de un año a los EID, mientras que la otra mitad había completado el año como usuario. Este dato no resulta menor, indicando que los espacios logran retener a los usuarios durante un tiempo bastante considerable.

Gráfico $n^{\circ}$ 2. Antigüedad de concurrencia de los usuarios de los EID 


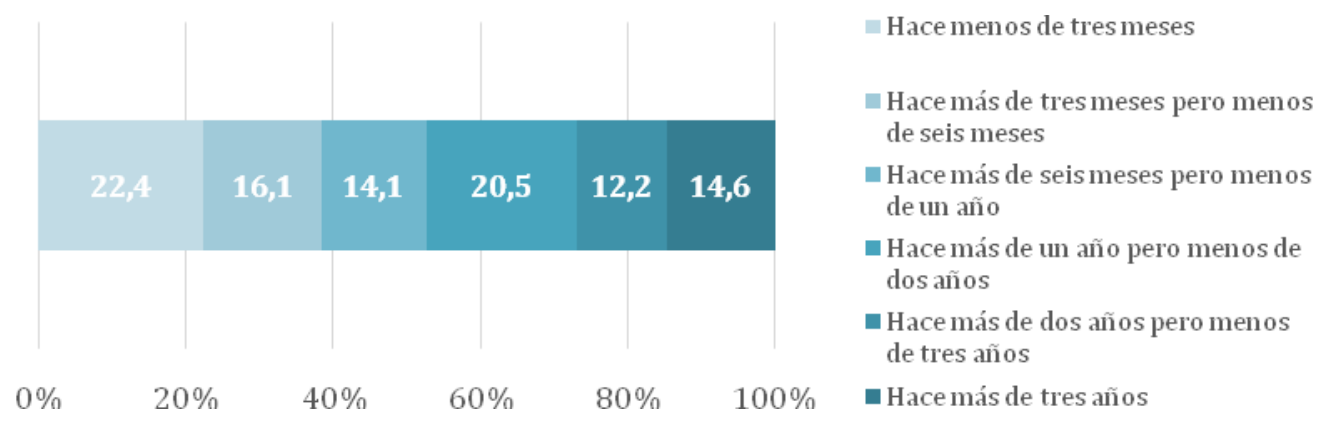

Fuente: procesamiento propio en base a relevamiento de usuarios - BASE: 206

Respecto a la frecuencia con la que acuden los usuarios a los espacios, un 3,9\% acude todos los días de la semana, $10,7 \%$ entre 3 y 5 días a la semana y la gran mayoría de usuarios $(74,1 \%)$ entre 1 y 2 días a la semana. Aquellos usuarios con un contacto más esporádico con los EID no representan más del 15\%.

Por último, en una visita típica, la gran mayoría de los usuarios (82\%) permanecía en el EID entre una y dos horas, $11,2 \%$ se quedan menos de una hora y $4,9 \%$ pernoctaba entre tres y cinco horas.

\subsubsection{Usos de Internet en el espacio EID}

Consultados a los usuarios de cómo utilizaban las instalaciones del EID, al igual que en la Encuesta de usos sobre TIC (EUTIC, 2013) la mayoría manifestaron utilizar Internet para comunicarse vía correo electrónico $(67,3 \%)$, al igual que acceder a redes sociales electrónicas como Facebook (44,4\%).

En segundo lugar, los usuarios manifestaron buscar información para estudiar $(56,1 \%)$, consultar enciclopedias y/o wikis (42\%), o descargar materiales que han dejado sus docentes $(32,7 \%)$. No es menor el porcentaje de usuarios que realizaron un curso a distancia $(20,5 \%)$. 
Gráfico $n^{\circ}$ 3. Tipos de usos de Internet en los espacios EID

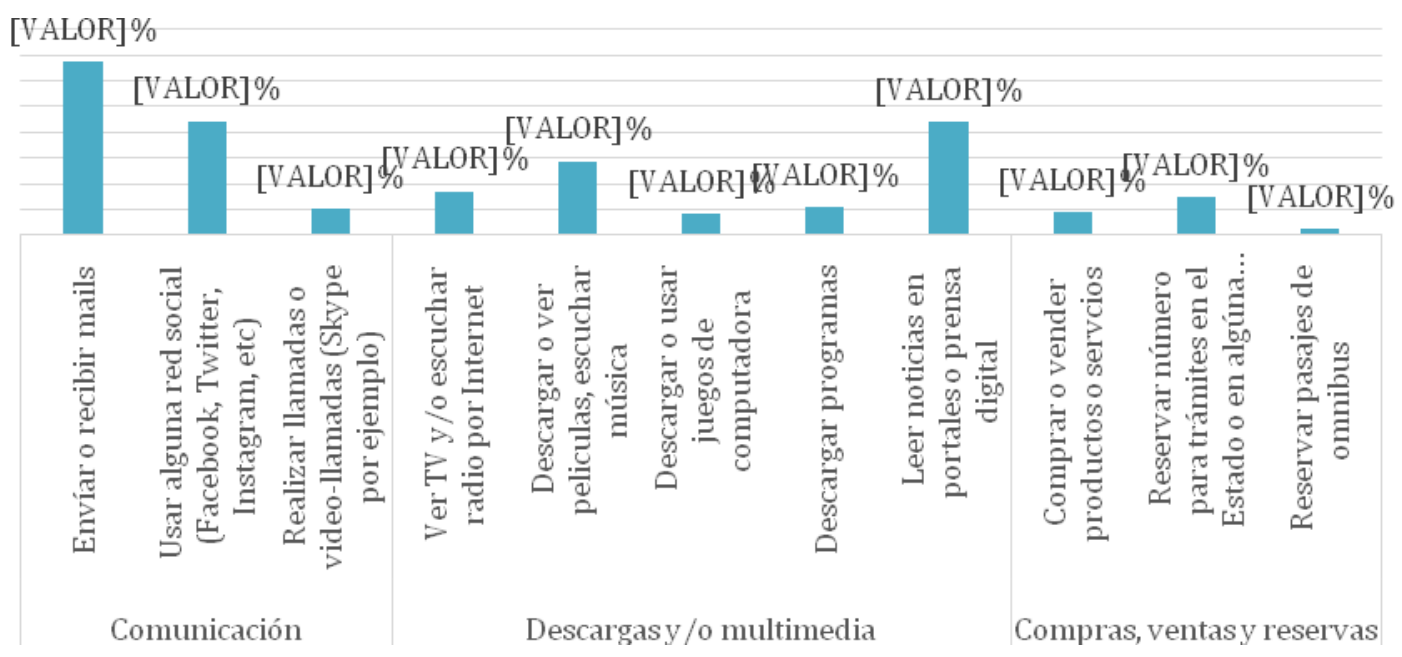

Fuente: procesamiento propio en base a relevamiento de usuarios - BASE: 206

En tercer orden los usuarios también utilizaron Internet en el EID para leer o descargar noticias en Internet (43,9\%) información en general (36,6\%) e información sobre contenidos de salud en general, o contenidos multimedia como música o películas $(28,8 \%)$.

No son pocos los usuarios que también buscaron información para su trabajo $(20,5 \%)$ o buscan empleo (20\%).Aquellos usos considerados avanzados como reservar número para trámites $(14,6 \%)$, descargar programas $(10,7 \%)$ o comprar o vender productos y servicios $(8,8 \%)$.

\subsection{EI mapa factorial y de correspondencias de los EID}

El modelo ACM logra explicar prácticamente un 17\% de la variabilidad de los datos que queremos representar y según el algoritmo de Benzecri (1979), la primera dimensión alcanza un $42,51 \%$ de la variabilidad explicada, mientras que la segunda dimensión roza el 27,08. Por lo tanto, la variabilidad en su conjunto es de casi un $70 \%$, siendo un indicador más que aceptable para proceder con el análisis.

Cuadro $n^{\circ}$ 1. Inercia explicada por cada uno de los factores

\begin{tabular}{|c|c|c|c|c|c|}
\hline \multirow{2}{*}{ Factor } & Valor propio & \% Inercia & $\begin{array}{c}\text { Valor propio } \\
\text { corregido (*) }\end{array}$ & \% Inercia (1) & \% Acumulado \\
\hline 1 & 0,201741 & $9,04 \%$ & 0,018284 & $42,51 \%$ & $42,51 \%$ \\
\hline
\end{tabular}




\begin{tabular}{|c|c|c|c|c|c|}
\hline 2 & 0,176544 & $7,91 \%$ & 0,011647 & $27,08 \%$ & $69,59 \%$ \\
\hline 3 & 0,142119 & $6,37 \%$ & 0,004988 & $11,60 \%$ & $81,19 \%$ \\
\hline 4 & 0,135669 & $6,08 \%$ & 0,00405 & $9,42 \%$ & $90,61 \%$ \\
\hline 5 & 0,110806 & $4,97 \%$ & 0,001347 & $3,13 \%$ & $93,74 \%$ \\
\hline 7 & 0,108094 & $4,85 \%$ & 0,00114 & $2,65 \%$ & $96,39 \%$ \\
\hline 8 & 0,099733 & $4,47 \%$ & 0,000611 & $1,42 \%$ & $97,81 \%$ \\
\hline 9 & 0,096382 & $4,32 \%$ & 0,000444 & $1,03 \%$ & $98,84 \%$ \\
\hline 10 & 0,092554 & $4,15 \%$ & 0,000287 & $0,67 \%$ & $99,51 \%$ \\
\hline
\end{tabular}

Fuente: procesamiento propio en base a relevamiento de usuarios - BASE: 206

En cuanto a los factores, la edad, y la educación de los usuarios son aquellos variables que explican más la expansión del mapa ACM y los perfiles se distinguen fundamentalmente por estas condicionantes. El eje de las X inciden aquellos elementos que hacen al acceso TIC de los usuarios previo al EID, es decir a la brecha digital de acceso, o el "capital digital material", mientras que en el eje de las $\mathrm{Y}$ se encuentran aquellas condiciones socio-demográficas, como el nivel educativo de los usuarios. La edad incide en ambos factores, lo que sugiere que existe una correlación de esta variable tanto en el acceso material TIC como en el nivel educativo de los usuarios.

Según el mapa, el cuadrante $+\mathrm{X}+\mathrm{Y}$, se encontrarán aquellos usuarios del EID, más jóvenes y dependientes de la política social TIC de Ceibal. Se trata de un espacio de usuarios "excluidos" digitalmente, esencialmente varones, sin acceso a Internet desde su hogar. Por lo tanto, aquí se encontraría parte del público objetivo de los telecentros. A la misma altura, en el cuadrante $-\mathrm{X}+\mathrm{Y}$, estarían ubicados también parte del público objetivo, pero con mejores condiciones de acceso TIC en el hogar. Disponen de acceso a Internet desde el hogar, al igual que dispositivos propios o de políticas TIC (Plan Ibirapitá). Se trata de usuarios, en su mayoría mujeres, de edad avanzada (mayores de 60 años), bajo nivel educativo, que acuden con cierta frecuencia semanal al EID, al menos una hora. 
El cuadrante $-\mathrm{X}-\mathrm{Y}$ es el espacio antagónico. Comprende a los usuarios en mejor posición de acceso TIC, y mejores niveles de formación para utilizar las TIC. Son mujeres, por fuera de la política social TIC, que acuden esporádicamente al EID, fundamentalmente para capacitarse y/o realizar algún curso de alfabetización digital. Por último, el espacio $+\mathrm{X}-\mathrm{Y}$ resulta similar al espacio de usuarios anterior, con la diferencia que estos participantes son más jóvenes y acuden algo de más tiempo a los telecentros.

Gráficos $n^{\circ}$ 4, 5 y 6: Mapa factorial. Incidencia de variables estudiadas y clasificación según Usuarios de los EID. Según el Censo de Usuarios EID, 2017.

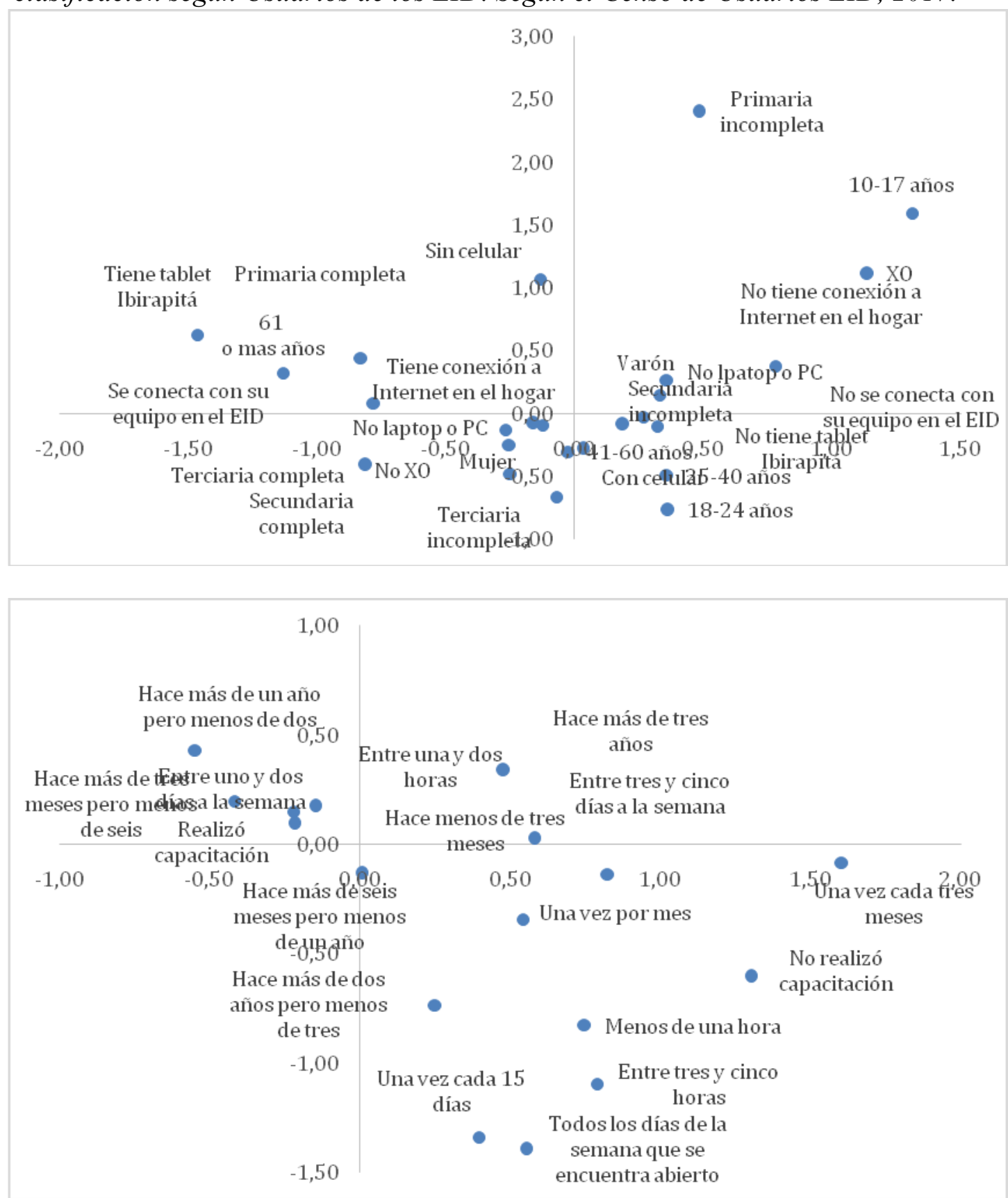




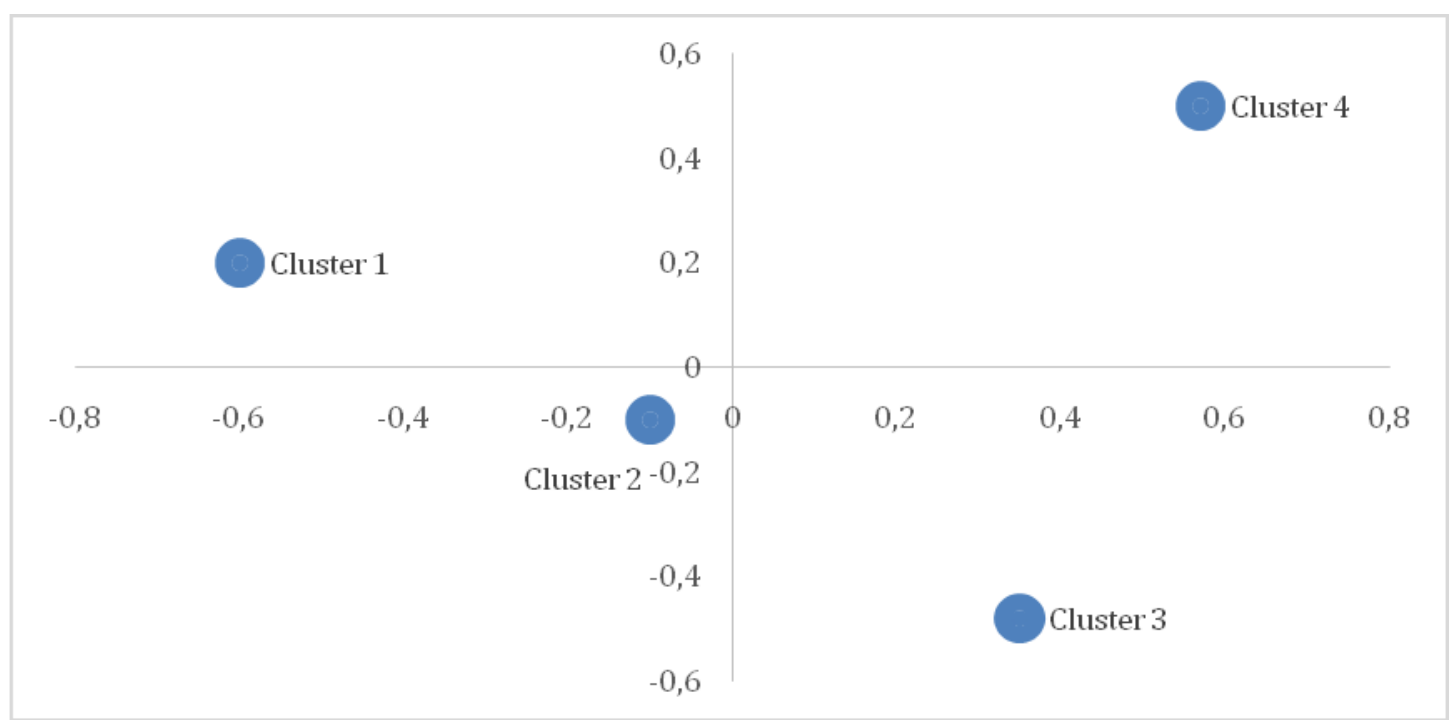

Fuente: Elaboración propia en base a datos de censo a usuarios EID, 2017.

El agrupamiento de usuarios determinado por el modelo ACM definió como solución óptima cuatro conglomerados, alojados casi por igual en los diferentes espacios que describimos con anterioridad (ver mapa ACM). La división valida los diferentes públicos que acuden a los EID, lo cual interpela que si bien la política social TIC es de carácter universal y libre acceso, no todos los usuarios traen consigo las mismas características socio-demográficas y de acceso TIC, por lo que se deberían desarrollar diferentes iniciativas de apropiación digital.

\subsection{La apropiación de los diferentes perfiles de usuarios}

Con los diferentes conglomerados, buscamos caracterizar ya no sólo posicionalmente a los usuarios, sino de acuerdo a sus características porcentuales. El grupo $n^{\circ} 1$ de usuarios se ubica mayoritariamente en el cuadrante $-X+Y$. Se trata de usuarios "vinculados", en su mayoría de mujeres (82\%), mayores a 60 años $(79,5 \%)$ que en su totalidad asistieron a un curso de capacitación y/o alfabetización, con más de un año de antigüedad en el EID (51,3\%) y que acude entre uno y dos días a la semana $(84,6 \%)$. Casi la mitad $(46,2)$ tienen como máximo nivel instructivo alcanzado primaria completa. La mitad de estos usuarios tiene tableta del Plan Ibirapitá, y acude con ella. Por lo tanto, dependen de una política TIC, y acuden a los EID en procura de alfabetizarse digitalmente. 
El grupo n² lo conforman usuarios "recientes" (cuadrante $-\mathrm{X}-\mathrm{Y}$ ), ya que más de la mitad (70,1\%) no tienen más de seis meses de antigüedad. Lo integran usuarios de todas las edades, que acceden desde sus hogares a las TIC (77,3\% tiene acceso desde un laptop desde su hogar y más del $80 \%$ a conexión de Internet). Al igual que el cluster anterior, en su mayoría acuden de una a dos veces por semana al EID $(87,6 \%)$ entre una y dos horas $(89,7 \%)$. A diferencia del primero, el nivel educativo de estos usuarios es levemente mayor, teniendo la mayoría secundaria incompleta $(58,8 \%)$, pero también encontrándose personas con nivel universitario $(30 \%)$.

Entre el cuadrante $-\mathrm{X}-\mathrm{Y}$ y $-\mathrm{X}+\mathrm{Y}$ se encuentran los usuarios "promedio". Son usuarios mujeres, también de todas las edades, aunque más del 50\% tiene entre 25 y 40 años. De similares características de acceso TIC previo a su llegada al EID, más del 50\% supera el nivel educativo de secundaria completa, e inclusive más del $20 \%$ estudios terciarios. Si bien hay usuarios que acuden todos los días al EID dentro de este cluster $(23,1 \%)$, también hay otros que acuden menos de una vez al mes $(19,2 \%)$. No obstante, no utilizan por demasiado tiempo las instalaciones. La gran mayoría acude menos de una hora $(61,5 \%)$, y en relación al resto de perfiles, sólo un 40\% realizó algún tipo de capacitación. Por lo que su contacto con la política si bien es frecuente, es más tenue.

Por último, en el espacio $+\mathrm{X}+\mathrm{Y}$ están los usuarios "adolescentes" integrándose beneficiarios del Plan Ceibal (80\%). Es un grupo con la mayor cantidad de usuarios varones (40\%), y con mucha presencia en los EID (más de un 20\% acude entre tres y cinco días a la semana, y $64,7 \%$ entre uno y dos días). Son los que más dependen de estos espacios, ya que menos del 25\% accede a Internet desde su hogar.

¿Qué sucede con los usos en el EID según estos perfiles de usuarios? Los gráficos $\mathrm{n}^{\circ} 8, \mathrm{n}^{\circ} 9 \mathrm{y} \mathrm{n}^{\circ} 10$ muestran los usos de los diferentes clusters. 
Gráficos nº 7, 8 y 9: Usos de Internet en el EID según Cluster. En porcentaje de usuarios. Censo de Usuarios EID, 2017.
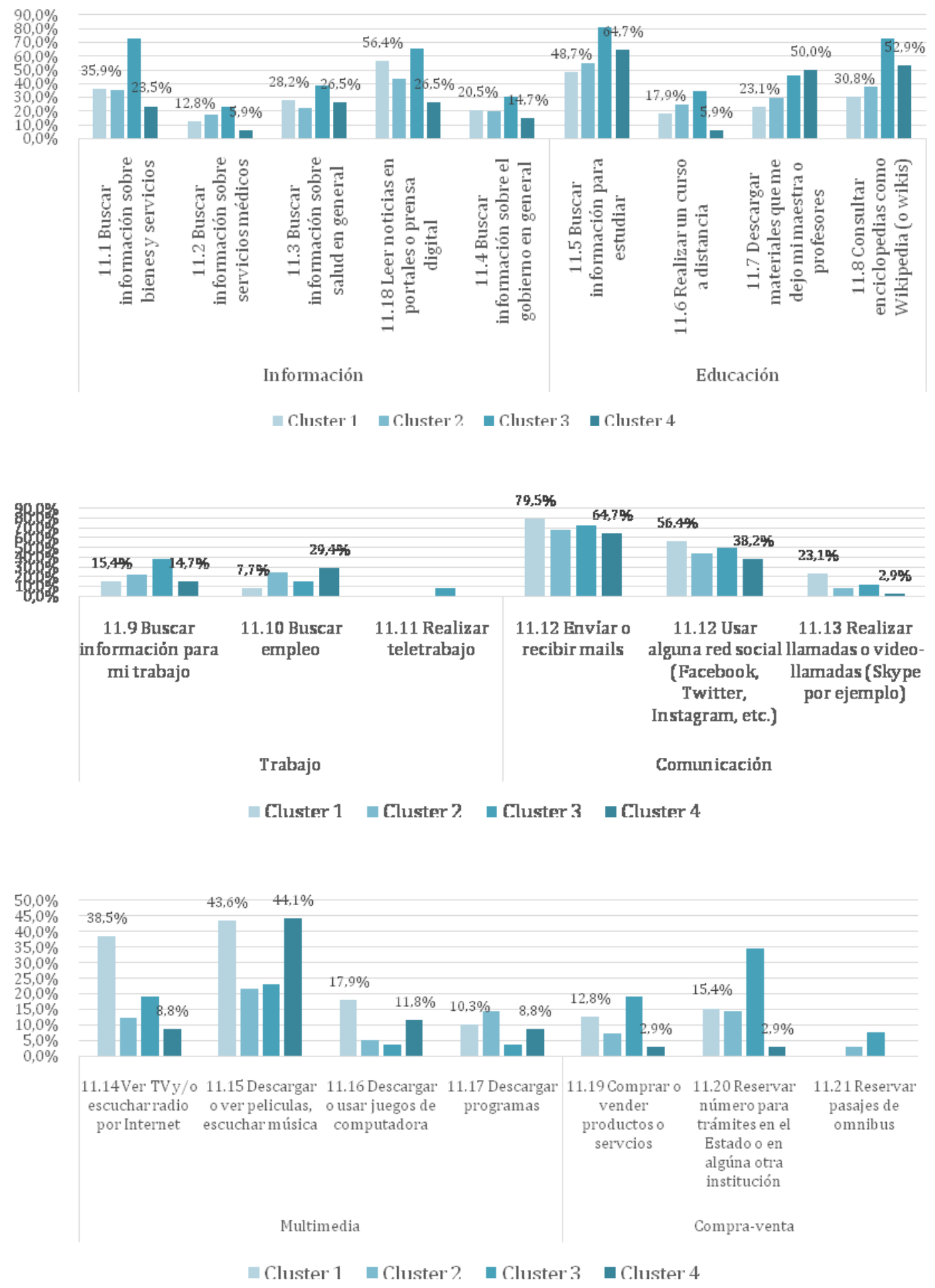

Fuente: Elaboración propia en base a datos de censo a usuarios EID, 2017.

Prácticamente todos los perfiles, con mínimas diferencias, utilizan Internet dentro de los EID para comunicarse vía correo electrónico o redes sociales electrónicas, 
lo cual no escapa al promedio de internautas uruguayos. No obstante, existen ciertas diferencias en cuanto al contenido recreativo. El perfil de usuarios "vinculados", aquellas mujeres adultas, que acuden con su dispositivo al telecentro (tableta del Plan Ibirapitá), son las que más destacan en Ver TV, o ver películas (40-45\%), junto con descargar juegos (18\%). Si bien, son un grupo alfabetizado e incluido digitalmente, el uso que realizan de las TIC dentro del EID es netamente lúdico respecto al resto., pese a mantenerse al día buscando noticias (56\%). Algo similar ocurre con los usuarios adolescentes, los cuales utilizan el EID en procura de información para estudiar o que le dejó el maestro/a $(64,7 \%$, $50 \%)$ o consulta de wikis $(52,9 \%)$, junto con descargar material multimedia $(44,1 \%)$, pero también buscar empleo $(30 \%)$.

Los usuarios "recientes" no destacan en particular en ningún uso respecto al resto. Se comunican vía correo (68\%) y redes sociales (44\%), realizando un uso bastante "puntual" en lo que refiere al resto de contenidos. Destacan en buscar trabajo $(24,7 \%)$, buscar información para su trabajo $(21,6 \%)$ o descargar programas $(14,4 \%)$.

Por último, los usuarios "promedio" sin tener la mayor exposición al EID, pero si teniendo las mejores condiciones sociodemográficas (mayor nivel educativo), y de acceso TIC en el hogar, son los que tienen mayor apropiación digital. Utilizan Internet dentro del EID para todo a excepción de recrearse. Se incluyen usos estratégicos y productivos como buscar información sobre bienes y servicios (70\%), buscar información para estudiar (80\%), buscar información para el trabajo (casi 40\%), reservar número para trámites con el Estado (casi 35\%) e inclusive comprar o vender por Internet (casi 20\%).

\section{Discusión y reflexiones finales}

De acuerdo a los análisis realizados en base al censo de usuarios de los Espacios de Inclusión Digital de la empresa de telecomunicaciones ANTEL, y a partir de los datos descriptivos generales como el análisis por ACM y cluster, se confirma en cierto modo la reproducción de las desigualdades digitales en el uso realizado. La política de acceso comunitario a Internet mitiga el impacto de la desigualdad del acceso pero, paradójicamente impacta favorablemente en aquellos usuarios 
con mejores condiciones de partida. Mejora la apropiación en los usuarios con mayor nivel educativo, con acceso y conocimiento de TIC previo a su llegada al EID y motivados en alfabetizarse digitalmente. Es decir, los menos relegados digitalmente dentro de esta población de usuarios.

La política tiene un fuerte componente de integración social dado que dentro del público objetivo se encuentran usuarios más excluidos en términos de acceso y uso TIC, sino también aquellos con mejor "background" digital.

La gran mayoría de usuarios son mujeres de 40 a 60 años de edad, con nivel secundario o inferior incompleto, tienen un contacto previo con las TIC y la gran mayoría dispone de conexión a Internet. En línea con otras investigaciones (Rivoir et. al., 2019) y contrario a las desventajas que experimentan las mujeres en el acceso y uso TIC, son las más proclives a acudir a estos espacios respecto a los varones, especialmente las mayores. Se puede suponer que existe cierta "proactividad" por adquirir algún nuevo tipo de conocimiento para no quedar excluidas del mundo de la virtualidad. Esto confirma lo encontrado en estudios anteriores (Rivoir et al., 2019). Se trata de un perfil de usuarios que es el de mayor antigüedad, con más tiempo de permanencia en el EID.

En el otro extremo se encuentran los usuarios más jóvenes, con amplia experiencia en el uso TIC, que acuden esporádicamente y para realizar tareas puntuales. Estos resultados también son coincidentes con los antecedentes de investigaciones en otro países (Peña et al, 2015; Proenza, 2015; Benitez Larghi, 2012), lo que evidencia la motivación de las mujeres para avanzar en la apropiación de las TIC y también como sostiene Benitez Larghi (2012) deja a la vista la necesidad de los jóvenes de acompañamiento y espacios de inclusión digital contrario a la idea de este sector como "nativos digitales" y la naturalización de su incorporación a la digitalización y sus beneficios.

En base a otros estudios realizados (Rivoir et. al., 2020; Rivoir, 2020b) se puede confirmar también la vinculación de la dinámica y participación en los EID, con otras políticas de inclusión digital como la de Ibirapitá orientada a personas mayores o Ceibal orientada a estudiantes, que cubren las necesidades de acceso a dispositivos y conectividad, pero generan más demandas de apoyo para el desarrollo de competencias digitales. 
Estos hallazgos resultan centrales para replantear la política de telecentros, ya no como un espacio de acceso a infraestructura TIC para público vulnerable exclusivamente, sino para un público más amplio, lo que es contrario a lo planteado en otros estudios sobre telecentros (Celedón y Razzeto, 2009: Delgadillo, Gómez y Stoll, 2002; Benítez Larghi et. al., 2012) que plantean como objetivo primordial la creación de estos espacios para población de desventaja. Parte de este cambio se debe a la difusión de las TIC entre la población y el acceso por gran parte de la misma a dispositivos y servicios de conectividad. La asistencia a los telecentros de sectores con acceso a dispositivos y conectividad cuestiona la concepción inicial y obliga a entender la desigualdad digital o brecha digital en forma más compleja, incorporando las desigualdades en el desarrollo de competencias, habilidades y en la apropiación de las TIC que es definitiva lo que estos usuarios de perfiles con mejores condiciones de posesión de tecnología y capacidades educativas y culturales individuales van a buscar al centro. Esto es evidencia en que se encontraron múltiples perfiles de usuarios, incluso muchos que ya están incluidos digitalmente. Asisten allí por diversas razones como para perfeccionar sus conocimientos a nivel usuario sobre ofimática o presentaciones; para buscar o cambiar de empleo, buscar materiales de estudio desde sus propios dispositivos, realizar trámites con el Estado, aprender a comprar en Internet, entre otras actividades. Esto combina por lo tanto, necesidades de acceso y conectividad tanto como de apoyo para el aprovechamiento de estos recursos y el acceso, incluso cuando hay condiciones tecnológicas en el hogar. Más de una cuarta parte de los asistentes, son beneficiarios de otras políticas públicas de inclusión digital (computadoras del Ceibal o tablets del Ibirapitá), mientras que más de la mitad contaba con celulares inteligentes y 73,7\% accedían a algún tipo de conexión a Internet desde el hogar.

En el tiempo libre, los usuarios utilizan Internet para comunicarse mediante redes sociales electrónicas y correo electrónico, al igual que buscar información en general, para estudiar o de contenidos de salud. Al igual que otros estudios (Escuder, 2010; Rivoir y Escuder, 2018), el tipo de uso TIC en los EID no resulta diferente a los usos encontrados para la población de Uruguay en general. Al igual que en el acceso, la política de telecentros y alfabetización digital no parecería 
alterar está lógica, especialmente en la población adulta, siendo los principales motivos para usar Internet el comunicarse e informarse. Esto parece confirmar los temores que se planteaban en relación a los telecentros en otros estudios que afirman la importancia de que las políticas estuvieran orientadas específicamente a objetivos de desarrollo de competencias, orientadas por los beneficios y la utilidad para las personas, tal y como sostuvieron Delgadillo, Gómez y Stoll (2002) y Barón y Gómez (2012).

Por el contrario, los usuarios menos vinculados, especialmente los más jóvenes, son aquellos que realizan un uso más productivo respecto al resto. Usos que requieren mayores destrezas y habilidades como buscar información para el trabajo o información para realizar trámites en el Estado, o vender y comprar. Lo que parece dar cuenta de persistentes necesidades de acceso y conectividad por parte de esta población.

El componente lúdico y de recreación en Internet (ver TV en línea, películas u otro contenido multimedia) paradójicamente destacan en los usuarios más "vinculados", es decir, en su mayoría mujeres, alfabetizadas digitalmente. Ello supone que inclusive para recrearse en Internet se deben de disponer de ciertas competencias digitales.

Respecto de las hipótesis de este trabajo, el primer supuesto sostenía que los usuarios de los EID realizan un uso significativo de Internet más allá de las desigualdades sociodemográficas pre-existentes que portan los usuarios. La segunda hipótesis sostiene lo contrario. Los usos dentro del EID reproducen los tipos de uso promedio en Uruguay. La tercera hipótesis sería una situación intermedia donde los EID logran mitigar algunas desigualdades digitales, pero no en todos los usuarios por igual. A partir del análisis de perfiles de usuarios se corrobora la tercera hipótesis pues se observa que los EID mitigan los impactos negativos de la brecha digital y el tipo de uso, pero en una parte bastante restringida de los usuarios. Paradójicamente aquellos incluidos previamente (jóvenes, de alto nivel educativo) son los que realizan un uso más productivo y significativo de las instalaciones. Mientras que aquellos con competencias adquiridas en el propio telecentro reproducen los usos promedios de los internautas uruguayos, especialmente el componente lúdico y de recreación. Sería 
importante en este sentido medir el tipo de uso de estos usuarios pero por fuera de las instalaciones de los EID en futuros estudios.

Es así que resulta importante reconceptualizar los usos. En tal sentido, emerge de este estudio que el uso para entretenimiento y recreación del telecentro, es importante para muchos sectores que no acceden a otros medios y espacios recreativos. El espacio de encuentro y sociabilidad presencial o virtual tiene un componente de integración social que hace al contexto y a la sociabilidad local.

Cabe concluir que los telecentros como ámbitos de acceso público y colectivo, tienen su vigencia en muchos aspectos dado que mantienen la asistencia de personas que se ven necesitadas de acceso o de apoyo para la incorporación de las TIC en sus vidas. La diferenciación encontrada en el aprovechamiento por parte de los distintos sectores de la población, indica que es importante ajustar las acciones a las necesidades de los distintos públicos. Fundamentalmente, hacer esfuerzos ingentes para que los asistentes puedan romper la segunda brecha y avancen sobre un uso profundo de las TIC y que encuentren beneficios para el mejoramiento de sus vidas.

En tal sentido, la revisión de estos centros debe estar orientada a reforzar el apoyo para la apropiación y revisar su metodología de trabajo. Esto es coincidente con otros estudios de casos más recientes sobre telecentros (Ramírez Placencia, 2014; Velloso y Castanheira, 2019). En cuanto al apoyo y acompañamiento, parece confirmar la importancia de los coordinadores, docentes y otros mediadores en relación a la formación, que ha sido frecuentemente planteado en estudios anteriores (Rivoir et alt, 2018; Rivoir et alt,2020; Escuder, 2010, Proenza, 2015; Celedón, 2012). Cabe destacar que tanto el perfil de los usuarios como los usos que realizan dan cuenta de la necesidad de ligar esta formación a las necesidades de los y las usuarias de forma tal de reforzar la motivación y aprovechamiento de los aprendizajes y de lograr el desarrollo de habilidades y competencias digitales que contribuyan a mejorar sus condiciones de vida.

\section{Referencias bibliográficas}

Baca, C., Belli, L., Huerta, E., Velasco, K. (2018). Redes Comunitarias en América Latina: Desafios, Regulaciones y Soluciones. Reston: Internet 
Society. Recuperado de

https://www.academia.edu/38075807/Redes Comunitarias en Am\%C3\% A9rica Latina Desaf\%C3\%ADos Regulaciones y Soluciones (Fecha de consulta: 29/03/2021)

Barón, L., Gómez, R. (2012). Relaciones sociales y sensación de conexidad. Usos de cibercafés, telecentros y bibliotecas en Colombia. Anuario Electrónico de Estudios en Comunicación Social "Disertaciones", 5(1). http://erevistas.saber.ula.ve/index.php/Disertaciones/ (Fecha de consulta: 29/03/2021)

Benítez Larghi, S., Aguerre, C., Calamari, M., Fontecoba, A., Moguillansky, M., Orchuela, J., Ponce de León, J. (2012). La apropiación del acceso a computadoras e Internet por parte de jóvenes de sectores populares urbanos en la Argentina. En: Proenza, F. J. (Ed.) Tecnología y cambio social: El impacto del acceso público a las computadoras e internet en Argentina, Chile y Perú. Lima: IDRC-CRDI; IEP. (América Problema, 35)

Benzecri, J. P. (1979). Sur le calcul des taux d'inertie dans l'analyse d'un questionnaire. Les cahiers de l'analyse des données, IV(3), 377-388.

Bonilla, M., Cliche, G. (2001). Internet y sociedad en América Latina. Fundación Acceso. Costa Rica.

Camacho, K. (2001). Internet: ¿Una herramienta para el cambio social?. México: FLACSO.

Celedón, M. A., Razeto, A. (2009). La transformación de puntos de acceso en nodos de conocimiento: análisis de diez experiencias de telecentros comunitarios en América Latina. Colección Documentos de Proyectos, LC/W. 233, CEPAL Santiago de Chile.

Chamorro, M. F. (2014) Inclusión digital y telecentros: análisis de experiencias de tres telecentros en Alto Paraná, Paraguay. ACADEMO Revista de Investigación en Ciencias Sociales y Humanidades, 1(1), 2-14. Recuperado de https://1library.co/document/y9gv73lq-inclusion-digitaltelecentros-analisis-experiencias-telecentros-parana-paraguay.html (Fecha de consulta: 29/03/2021)

Credé, A., Mansell, R. (1998). La sociedad del conocimiento... en síntesis. Tecnología de la información para un desarrollo sustentable. IDRC. Recuperado de https://idl-bncidrc.dspacedirect.org/handle/10625/14636? show=full (Fecha de consulta: 29/03/2021) 
De la Maza, M., Maeso, O., Gutiérrez, F., Wohlers, M. (2007). Assessment of the status of the implementation and use of ICT access points in Latin America. Santiago de Chile: CEPAL.

Di Maggio. P., Hargittai, E., Celeste, C., Shafer, S. (2004). From Unequal Access to Differentiated Use: A Literature Review and Agenda for Research on Digital Inequality. Recuperado de http://www.eszter.com/research/pubs/dimaggio-etal-digitalinequality.pdf (Fecha de consulta: 29/03/2021)

Durán, E. (2009). Tecnologías de información y comunicación para el desarrollo: Una mirada etnográfica a un Infocentro venezolano. Anuario Electrónico de Estudios en Comunicación Social "Disertaciones", 2(1), 125-160. Recuperado de https://revistas.urosario.edu.co/index.php/disertaciones/article/view/3971/2 935 (Fecha de consulta: 29/03/2021)

Escuder, S. (2010.). Estudio del impacto social. El acceso a las TIC en áreas rurales y pequeñas localidades: el caso de los centros MEC. Tesis de grado. Universidad de la República (Uruguay). Facultad de Ciencias Sociales. Recuperado de https://hdl.handle.net/20.500.12008/24672 (Fecha de consulta: 29/03/2021)

Finquelievich, S. (2000). TIC, desarrollo y reducción de la pobreza en América Latina y el Caribe. Recuperado de http://www.links.org.ar/infoteca/ticsypobrezalac.rtf

Finquelievich, S. (2004). Ambientes Urbanos Innovadores: El desarrollo local y regional en la Sociedad Informacional. VI Seminario Nacional de la Red de Centros Académicos para el estudio de gobiernos locales. Córdoba, 9 y 10 de Septiembre. Recuperado de http://biblioteca.municipios.unq.edu.ar/modules/mislibros/archivos/finquel ievich.pdf (Fecha de consulta: 29/03/2021)

Gascó-Hernández, M., Equiza-Lopez, F., Acevedo-Ruiz, M. (2007). Information Communication Technologies and Human Development: Opportunities and Challenges. Idea Group Publishing.

Gómez, R., Stoll, K. Delgadillo, K. (2002) Telecentros... ¿para qué? Lecciones sobre telecentros comunitarios en América Latina y el Caribe. Canadá: IDRC/CRDI.

Gómez, R., Hunt, P., Lamoureux, E. (1999). Telecentros en la mira: ¿Cómo pueden contribuir al desarrollo social? Revista Latinoamericana de 
Comunicación. Canadá: CHASQUI, Centro Internacional de Investigaciones para el Desarrollo (CIID).

Guerra, M., Jordán, V. (2010) Politicas públicas de la Sociedad de la Información en América Latina: ¿una misma visión?. Santiago de Chile: Documento de Proyecto CEPAL.

Hallberg, D. (2016). Telecentros en Bolivia: la atención en las mujeres. Revista Caracteres, 5(2), 145-167. Recuperado de https://www.researchgate.net/publication/314079328 Telecentros en Boli via la atencion en las mujeresTelecentres in Bolivia a focus on wom en (Fecha de consulta: 29/03/2021)

Hargittai, E. (2004). Internet Access and Use in Context. New Media \& Society, 6.

Hargittai, E., Hinnant, A. (2008). Digital inequality: Differences in young adults' use of the Internet. Communication Research, 35(5).

INE. (2019). Principales resultados Encuesta de Usos de Tecnologías de la Información y la Comunicación 2019. Instituto Nacional de Estadística del Uruguay. Recuperado de https://ine.gub.uy/web/guest/eutic//asset publisher/8nW0ZKdgKuqR/content/principales-resultadosencuesta-de-usos-de-tecnologias-de-la-informacion-y-la-comunicacion2019/maximized? 101_INSTANCE 8nW0ZKdgKuqR redirect $=\% 2 F w e b$ \%2Fguest $\% 2$ Feutic (Fecha de consulta: 29/03/2021)

Jang. J., Hessel, H., Dworkin, J. (2017). Parent ICT Use, Social Capital, and Parenting Efficacy. Computers in Human Behavior. doi: 10.1016/j.chb.2017.02.025.

Katzman, R. (2010). Impacto social de la incorporación de las nuevas tecnologías de información y comunicación en el sistema educativo. Serie Políticas Sociales, 166. CEPAL, Santiago de Chile.

Lamschtein, S., Rivoir, A. (2017). Desafíos para el estudio de las desigualdades digitales. Uso, habilidades y resultados tangibles. En: Pucci, F. (Coord.) El Uruguay desde la Sociología 15. Montevideo: Departamento de Sociología, Universidad de la República.

Lash, S. (2002). Critique of Information. Londres: Editorial Sage.

Livingstone, S., Helsper, E. (2010). Balancing opportunities and risks in teenagers' use of the internet: The role of online skills and internet selfefficacy. New Media \& Society, 12(2), 309-329. 
Lopez Roldan, P., Fachelli, S. (2015). Metodología de la Investigación Social Cuantitativa. Manual. Universidad Autónoma de Barcelona. Recuperado de http://pagines.uab.cat/plopez/content/manual-misc (Fecha de consulta, 05/10/2020).

Martínez, J. (2001) Internet y políticas públicas socialmente relevantes: ¿Por qué, cómo y en qué incidir? en Internet y sociedad en América Latina y el Caribe, investigaciones para sustentar el diálogo. IDRC - FLACSO. pp. 509-542. Recuperado de https://biblio.flacsoandes.edu.ec/libros/digital/44934.pdf (Fecha de consulta: 29/03/2021)

Norris, P. (2001). Digital Divide? Civic Engagement, Information Poverty and the Internet Worldwide. Cambridge University Press (subsequently published in Korean).

Peña - López, I. (2009). Midiendo el Desarrollo Digital para las Políticas Públicas: El papel del Gobierno. Ponencia presentada en la II Conferencia Internacional sobre Brecha Digital e Inclusión Social, Madrid, del 28-30 de octubre de. Recuperado de https://earchivo.uc3m.es/handle/10016/12465

Phillippi, A., Peña, P. (2012) Impacto del acceso público en dos telecentros: apropiación social de las TIC por parte de mujeres chilenas. En: Proenza, F. J. Tecnología y cambio social: El impacto del acceso público a las computadoras e internet en Argentina, Chile y Perú. Lima, IDRC-CRDI; IEP. (América Problema, 35)

Proenza, F. J. (Ed.) (2015). Public Access ICT across Cultures. Diversifying Participation in the Network Society- International Development Research Centre and MIT Press.

Ramírez Plascencia, D. (2014) Educación a distancia y políticas públicas en materia de telecentros digitales el caso del proyecto "CASA" de México. Cuadernos. Info, (35), 55-67. https://doi.org/10.7764/cdi.35.638 (Fecha de consulta: 29/03/2021)

Reygadas, L. (2008). Tres matrices generadoras de desigualdades. En: Ramírez, P. Ziccardi, A. Pobreza urbana, desigualdad y exclusión social en la ciudad del siglo XXI. México: Siglo XXI Editores.

Rivoir, A. (2012). Estrategias nacionales para la Sociedad de la Información y el Conocimiento en América Latina, 2000 - 2010. El caso de Uruguay. Tesis Doctoral uoc. Recuperado de 
https://www.tdx.cat/bitstream/handle/10803/132089/TESIS Doctoral Ana Rivoir.pdf? sequence $=1$

Rivoir, A. (2013). Enfoques dominantes en las estrategias para la sociedad de la información y el conocimiento: el caso uruguayo 2000 - 2010. Revista de Ciencias Sociales. (33), 11-30.

Rivoir, A., Escuder, S. (2018) Dispositivos digitales en el hogar: incidencia de las desigualdades y las políticas públicas de acceso a partir de un análisis multivariado. Observatorio (OBS*), 12(3), 295-311. Recuperado de http://obs.obercom.pt/index.php/obs/index

Rivoir, A., Morales, M. J., Casamayou, A. (2019). Usos y percepciones de las tecnologías digitales en personas mayores. Limitaciones y beneficios para. Revista Austral de Ciencias Sociales, 36, 293-311. Recuperado de http://revistas.uach.cl/index.php/RACS

Rivoir, A., Escuder, S., Liesegang, L. (2020). Usos y competencias digitales en personas mayores favorecidas por un plan de inclusión digital. Psicología, Conocimiento, Sociedad, 10(1), 3-27. http://dx.doi.org/10.26864/pcs.v10.n1.3

Rivoir, A. (2020). Revisión de antecedentes sobre One Laptop Per Child y discusión sobre sus resultados en América Latina. En: Ana Rivoir (Coord.) Tecnologías digitales y transformaciones sociales Desigualdades y desafios en el contexto latinoamericano actual. pp. 113-139. Buenos Aires: Consejo Latinoamericano de Ciencias Sociales. Editora Nómada. Recuperado de http://biblioteca.clacso.edu.ar/clacso/se/20200903055606/Tecnologiasdigitalespdf

Robinson, S. (2001). Hacia un modelo de franquicias para telecentros comunitarios en América Latina. En: Internet y Sociedad en América Latina y el Caribe. FLACSO Ecuador, Quito. (pp. 479 - 508)

Sabelli, M (2008) La información y el ciudadano en el entorno de la sociedad de la información. Ediciones de la Banda Oriental, CSIC, EUBCA. ISBN: 9789974105133

Selwyn, N. (2004). Reconsidering Political and popular understanding of the Digital Divide. New Media \& Society, 6, (3), 341-362.

Van Deursen, Van Dijk (2014). The digital divide shifts to differences in usage. New Media \& Society, 16, (3). 
Van Dijk, J. (2005). The Deepening Divide, Inequality in the Information Society. London, New Delhi: Sage Publications, Thousand Oaks ca.

Van Dijk, J. A. G. M. (2012). The Evolution of the Digital Divide - The Digital Divide Turns to Inequality of Skills and Usage. In: J. Bus, M. Crompton, M. Hildebrandt, \& G. Metakides (Eds.), Digital Enlightenment Yearbook 2012 (pp. 57-78). Amsterdam: IOS Press.

Velloso Maia, M. J, Castanheira, M. L. (2019) Inclusión digital y prácticas de lectura en un telecentro de una comunidad quilombola. Rev. Diálogo Educ., Curitiba, 19, (60), pp. 288-307. http://dx.doi.org/10.7213/1981416X.19.060.DS13 (Fecha de consulta: 29/03/2021)

\section{Notas}

[1] Datos disponibles en: https://www.itu.int/net4/itu-d/icteye/CountryProfile.aspx (Fecha de consulta 28/03/2021)

[2] Datos e informes disponibles en: https://www.ine.gub.uy/web/guest/encuestade-uso-de-la-tecnologia-de-la-informacion-y-las-comunicaciones (fecha de consulta 28/03/2021)

[3] https://rstudio.com/ (Fecha de consulta 28/03/2021)

[4] https://cran.r-project.org/web/packages/FactoMineR/index.html (Fecha de consulta 28/03/2021)

[5] https://www.usi.org.uy/programa-usi (Fecha de consulta 28/03/2021)

\section{Nota de contribución autoral}

Ambos autores contribuyeron con la elaboración general del artículo, colaborando en todos los apartados puntualmente, sobre todo en las correcciones propuestas por los evaluadores. No obstante, Ana Rivoir puso mayor énfasis en la construcción del Marco Teórico y su integración coherente, al igual que en la gramática general del texto, la discusión final y recomendaciones. Santiago 
Escuder realizó la metodología, objetivos, hipótesis, el procesamiento de los datos y aplicación de técnicas junto con la redacción de hallazgos principales y gráficos.

\section{Notas del editor}

El editor responsable para la publicación de este artículo fue Mario Barité. 